\title{
MODEL CALCULATIONS OF RECRYSTALLIZATION TEXTURE FORMATION BY GROWTH SELECTION
}

\author{
U. KÖHLER, E. DAHLEM-KLEIN, H. KLEIN and H. J. BUNGE
}

(Received July 1, 1991)

\begin{abstract}
Model calculations of recrystallization texture formation are carried out on the basis of growth selection according to the $40^{\circ}\langle 111\rangle$ orientation relationship. It is shown that the fastest growing "compromise" orientation depends very sensitively on the nature of the deformation texture components, their relative amount and their spread, as well as on the value of the rotation angle and the spread range of the growth rate law. On this basis the cube recrystallization texture as well as the brass recrystallization texture can be modelled without further assumptions. Also modifications of the recrystallization texture due to modifications of the starting deformation texture are sufficiently described by the model.
\end{abstract}

KEY WORDS Local growth rate, Mean linear growth rate, Compromise orientation, $40^{\circ}\langle 111\rangle$ rotation, Cube texture, Brass recrystallization texture.

\section{INTRODUCTION}

The process of primary recrystallization can be considered on the basis of nucleation and growth, terminated by final impingement of the growing grains. Under certain plausible assumptions for the kinetics of the nucleation and the growth process this leads to the well established Johnson-Mehl-Avrami kinetics describing the recrystallized volume fraction as a function of time.

In order to understand the formation of recrystallization textures the orientation dependences of both these fundamental processes must be taken into consideration. Thereby, two limiting assumptions can be made. One is the assumption of random distribution of the nuclei (Beck, 1949). Texture formation must then be attributed solely to growth selection. The opposite is that of isotropic growth (Burgers, 1931), in which case the orientation distribution of the nuclei determines the final recrystallization texture. Either of these assumptions has been supported by strong experimental evidence. This is by no means contradictory. It shows only that the experimental conditions in either case were chosen in such a way that the orientation dependence of the respective second process was in this case isotropic. In the most general case, it must be assumed that oriented nucleation will be followed by orientation selective growth and that the final recrystallization texture will thus depend on the orientation dependence of both.

It must be mentioned that the concept of nucleation and growth suffers from the uncertainty of what really is a nucleus. When a "nucleus" has become visible, 
some growth must already have taken place. Before that, one strictly cannot be sure, whether a certain configuration of the deformed microstructure will or will not develop into a nucleus, finally. Under this aspect, nucleation may be looked at as microscale growth. From a more practical aspect, however, it is convenient to subsume the early stages of rearrangement in the deformed microstructure under the term "nucleation".

The subsequent growth of a nucleus may be understood on basis of movement of large angle boundaries separating the virtually dislocation free recrystallized grains from the deformed matrix. In the typical primary recrystallization processes the dislocation energy must be assumed to deliver the main part of the driving force although contributions of the grain boundary energy may not always be completely negligible. It is well known, that the dislocation substructure, and hence the driving force, depends on the orientation of the deformed grain. Besides this, microinhomogenities of the deformed structure such as deformation bands or shear bands may considerably influence the local values of the driving force. The mobility of a moving large angle boundary is known to depend on the misorientation of the two neighbouring grains as well as on the orientation of the grain boundary itself, e.g. tilt or twist boundaries. Furthermore, also the local dislocation substructure may have further influence on the mobility. Taking all these parameters into account it seems to be virtually impossible to develop a comprehensive mathematical model which takes all these parameters quantitatively into account.

Nevertheless, however, the experimentally observed recrystallization textures are found to be "stable" with respect to a certain range of technological parameters and hence to certain variations of the deformed microstructure. It may, therefore, not be hopeless to look for the "essential" structural parameters on the basis of which the formation of recrystallization textures may be understood. In some earlier papers (Bunge and Plege, 1986 and 1987) we suggested a mathematical model which is on the one hand simple enough to allow numerical calculations and on the other hand takes the most important orientation dependent parameters into account. It is the purpose of the present paper to show that this model is well suited to explain the occurrence of the cube recrystallization texture as well as the texture of recrystallized brass.

\section{THE MATHEMATICAL MODEL}

It is assumed that the nuclei have an orientation distribution $f^{N}(g)$ defined by

$$
\frac{d N / N}{d g}=f^{N}(g)
$$

Each nucleus grows with a constant mean linear growth rate $\bar{W}(g)$ which depends on its orientation $g$. The growth rate is, however, independent of the growth direction. It is further assumed, that all the nuclei have been formed at the same time $t=0$ at which they start to grow. Furthermore, impingement of the growing grains is neglected. Hence, growth is finished at a certain time $t_{R}$ which is being chosen in such a way that the recrystallized volume is that of the whole sample. 
Under these assumptions the recrystallization texture can be written in the form

$$
f^{R}(g)=\frac{4 \pi}{3} N \cdot t_{R}^{3} \cdot f^{N}(g) \cdot \bar{W}^{3}(g)
$$

Thereby $N$ is the total number of nuclei. The recrystallization time $t_{R}$ is chosen in such a way that the normalization condition for $f^{k}(g)$ is fullfilled, i.e.

$$
\frac{4 \pi}{3} N \cdot t_{R}^{3} \cdot \oint f^{N}(g) \cdot \bar{W}^{3}(g) d g=1
$$

The average linear growth rate $\bar{W}(g)$ is obtained under the assumption that the local growth rate $W(\Delta g)$ depends only on the orientation difference or misorientation $\Delta g$ between the growing grain and the matrix grain into which it grows locally. It is further assumed that the average growth length $r\left(g^{D}\right)$, which has to be run through in the matrix grains of the orientation $g^{D}$, is proportional to the volume fraction of $g^{D}$-grains in the deformed matrix i.e. to the deformation texture $f^{D}\left(g^{D}\right)$. The time needed for the path $r\left(g^{D}\right)$ is given by

$$
t\left(g^{D}\right)=\frac{r\left(g^{D}\right)}{W(\Delta g)} \approx \frac{f^{D}\left(g^{D}\right)}{W(\Delta g)}
$$

The orientation $g$ of the growing grain is related to the orientation $g^{D}$ of the deformed matrix by

$$
g=\Delta g \cdot g^{D}
$$

Then the average linear growth rate of a growing grain of the orientiation $g$ is given by

$$
\frac{1}{\bar{W}(g)}=\oint \frac{f^{D}\left(g^{D}\right)}{W(\Delta g)} \cdot d g^{D}
$$

Equation 6 can be considered as the quantitative formulation of the concept of "compromise" texture formation considered by Schmidt, Lücke and Pospiech (1975) and Bunge (1966). The distribution of nuclei $f^{N}(g)$ must be considered separately. In a particular case of cold rolled brass studied by Plege (1983) it was concluded that the distribution of primary nuclei was proportional to the deformation texture

$$
\frac{d N^{0} / N^{0}}{d g}=f^{D}\left(g^{D}\right)
$$

In an early stage, however, the orientations of the nuclei could be changed by twinning according to the twinning law

$$
g_{i}^{t}=\Delta g_{i}^{t} \cdot g^{D}
$$

Thereby $\Delta g_{i}^{t}$ are several crystallographically equivalent twin relationships e.g. $60^{\circ}\langle 111\rangle$ rotations. In the most general case it must be admitted that a twin variant selection may occur. Furthermore, twins of higher generations may also occur. Under these assumptions the final orientation distribution function $f^{N}(g)$ of the nuclei was assumed to be constituted of the primary nuclei according to 
Eq. (7) with the twins of all generations

$$
f^{N}(g)=\sum_{n} v^{n} \cdot f^{n}(g)
$$

In the present paper we shall restrict our considerations on the mean growth rate $\bar{W}(g)$. The influence of the distribution of nuclei on the final recrystallization texture will be considered elsewhere. The mean growth rate $\bar{W}(g)$ depends essentially on the local growth rate $W(\Delta g)$. Orientation dependent growth rates $W(\Delta g)$ have been determined in several investigations following the classical measurement by Liebmann, Lücke and Masing (1956). To our knowledge, none of these measurements was, however, done in the complete misorientation space $\Delta g=\left\{\varphi_{1}, \Phi, \varphi_{2}\right\}$ depending on three orientation angles. Hence, model assumptions have to be used for $W(\Delta g)$. In the following numerical calculations it was assumed that $W(\Delta g)$ takes on its maximum value at $\Delta g=\Delta g_{0}$ and from there on drops to zero according to a Gauss-distribution with isotropic spread reaching the value $e^{-1}$ at the angular distance $\omega_{G}$. In order to avoid infinite values in Eq. (6) a small finite growth rate $W_{0}$ was assumed in great distance from $\Delta g_{0}$. Hence we put

$$
W(\Delta g)=W_{0}+W^{\text {Gauss }}(\Delta g)_{\Delta g_{0}, \omega_{G}}
$$

In some cases, also the deformation texture $f^{D}(g)$ was idealized in the form of an ideal orientation $g_{0}$ with Gaussian spread $\omega_{D}$ about it.

$$
f^{D}\left(g^{D}\right)=f^{\text {Gauss }}(g)_{g_{0}, \omega_{D}}
$$

Under these assumptions essentially four free parameters have to be considered, i.e. orientation $g_{0}$ and spread $\omega_{D}$ of the deformation texture and misorientation $\Delta g_{0}$ and spread $\omega_{G}$ of the local growth rate. Furthermore, deformation texture and growth rate function can be composed of several such components, each. The calculations were carried out using the series expansion

$$
\begin{gathered}
f(g)=\sum_{l=0}^{L} \sum_{\mu=1}^{M(l)} \sum_{v=1}^{N(l)} C_{l}^{\mu v} \ddot{T}_{l}^{\mu v}(g) \\
W(\Delta g)=\sum_{l=0}^{L} \sum_{\mu_{1}=1}^{M(l)} \sum_{\mu_{2}=1}^{M(l)} C_{l}^{\mu_{1} \mu_{2}}: \ddot{T}_{l}^{\mu_{1} \mu_{2}}(\Delta g)
\end{gathered}
$$

for both kinds of distribution functions. In this case Gaussian distributions of the form Eqs. (10) and (11) can be expressed by the coefficients

$$
C_{l}^{\mu v}=\frac{\exp \left\{-\frac{1}{4} l^{2} \omega^{2}\right\}-\exp \left\{-\frac{1}{4}(l+1)^{2} \omega^{2}\right\}}{1-\exp \left\{-\frac{1}{4} \omega^{2}\right\}} T_{l}^{\mu v}\left(g_{0}\right)
$$

Non-linear operations on distribution functions such as Eq. (2) and (6) are difficult to perform in terms of the coefficients. They were carried out in the orientation space in equidistant steps of $\left\{\Delta \varphi_{1}, \Delta \Phi, \Delta \varphi_{2}\right\}=5^{\circ}$ returning finally again to the series representation of the distribution functions which were extended up to $L=22$. 


\section{RESULTS OF NUMERICAL CALCULATIONS}

The orientation dependence of the mean growth rate $\bar{W}(g)$ was calculated numerically according to Eq. (6) starting with the local growth rate $W(\Delta g)$. The latter one was chosen according to Eq. (10) with $\Delta g=40^{\circ}\langle 111\rangle$ which corresponds to the results by Liebmann, Lücke and Masing (1956) extended into the

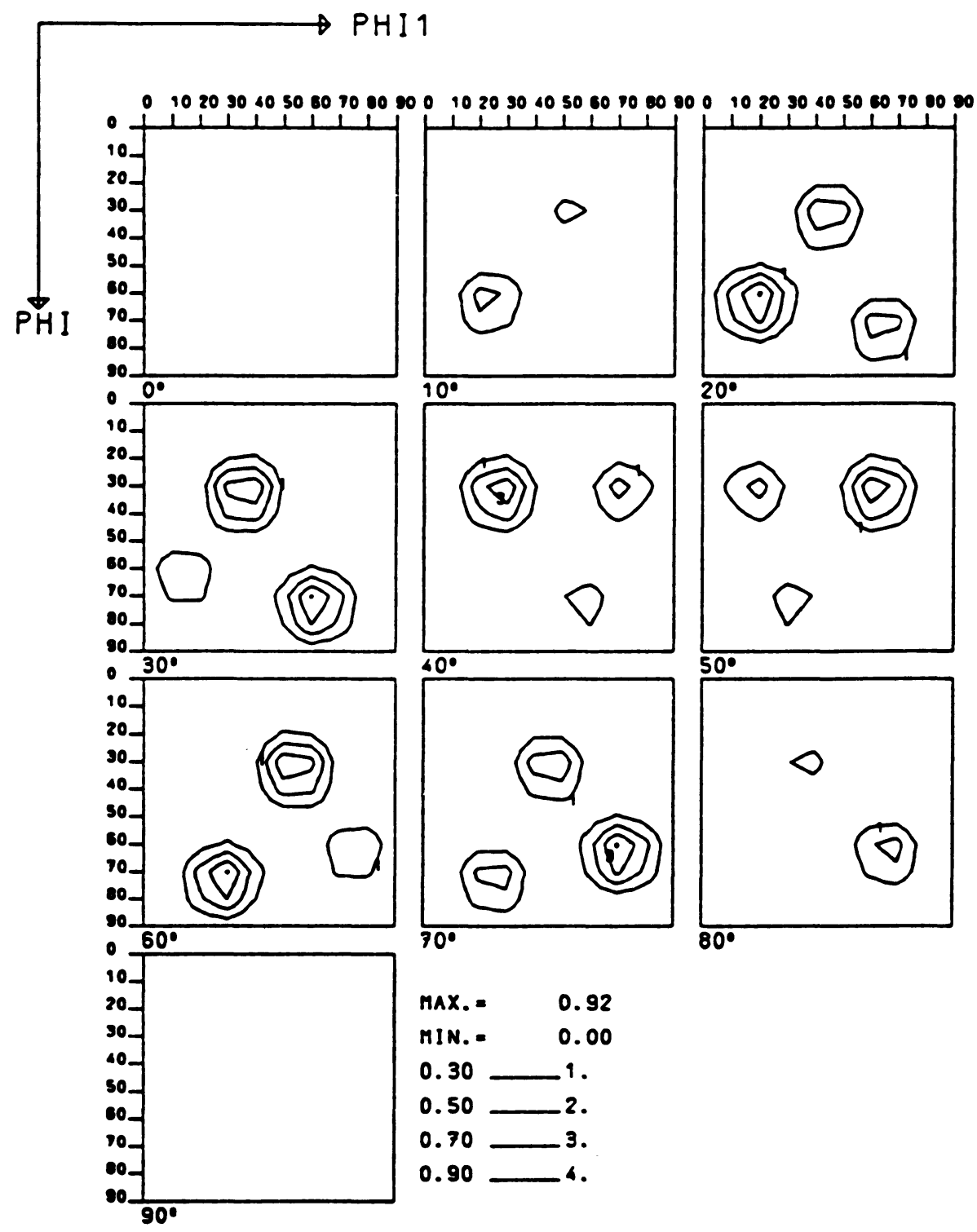

Figure 1 The local growth rate $W(\Delta g)$ as a function of the misorientation $\Delta g$ between growing grain and deformed matrix according to Eq. (10) with $\Delta g_{0}=40^{\circ}\langle 111\rangle, \omega_{G}=12^{\circ}, W_{0}=0$. 


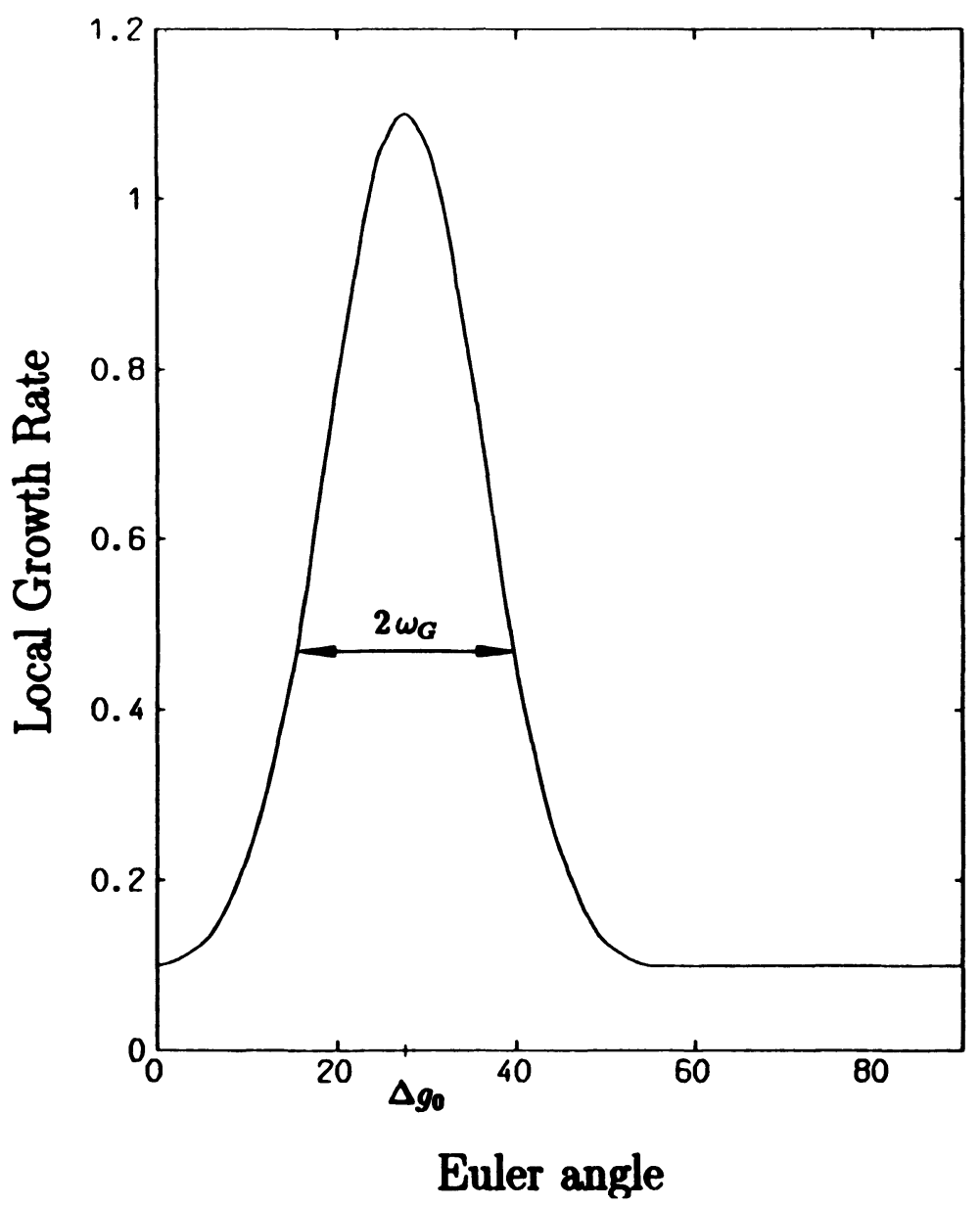

Figure 2 Linear section of the growth rate function $W(\Delta g)$.

Table 1 Ideal orientations of the deformation texture.

\begin{tabular}{lccr}
\hline & \multicolumn{3}{c}{ Orientation } \\
& $\phi_{1}$ & $\Phi$ & $\varphi_{2}$ \\
\hline $\mathrm{Cu}$ & $90^{\circ}$ & $35^{\circ}$ & $45^{\circ}$ \\
$\mathrm{S}$ & $59^{\circ}$ & $37^{\circ}$ & $63^{\circ}$ \\
$\mathrm{Br}$ & $35^{\circ}$ & $45^{\circ}$ & $0^{\circ}$ \\
$\mathrm{G}$ & $0^{\circ}$ & $45^{\circ}$ & $0^{\circ}$ \\
\hline
\end{tabular}


three-dimensional orientation space. This distribution function is shown in Figure 1. The constant value $W_{0}$ was chosen mainly in order to avoid infinitely high values in Eq. (6). This can be seen in Figure 2 which is a linear section through the maximum value of $W(\Delta g)$. In this case it was $W_{0}=0.1$. In the following calculations also slightly modified growth rate functions were used, the actual parameters $\Delta g_{0}, \omega_{G}, W_{0}$ of which will then be specified.

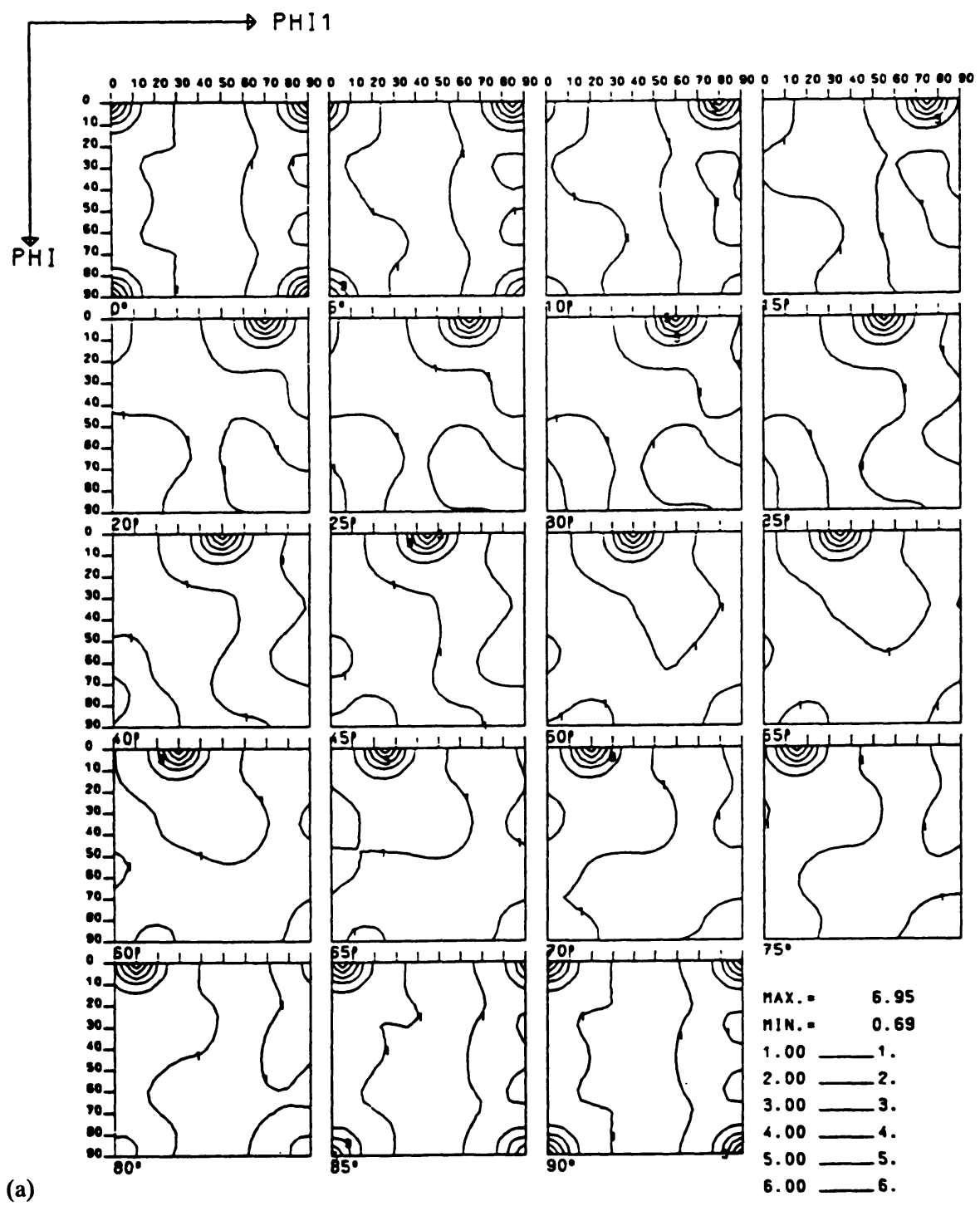

Figure 3 Mean growth rates for deformation textures consisting of only one ideal orientation $g_{0}$ with some spread $\omega_{D}$ about it. The local growth rate was chosen with $\omega_{G}=12.5^{\circ}, W_{0}=0.04$. (a) S-orientation $\omega_{D}=10^{\circ}$, (b) copper orientation $\omega_{D}=10^{\circ}$, (c) brass orientation $\omega_{D}=10^{\circ}$. 
Mean growth rates $\bar{W}(g)$ were calculated for different types of fcc deformation textures. In order to better distinguish the influences of various parameters of the deformation textures, these were idealized by the copper, brass, Goss, and S-Orientation as given in Table 1. The positions of these orientations were taken fixed, their respective spread values $\omega_{D}$ and volume fractions were, however, varied.

The rolling texture of high stacking fault fcc metals is assumed to be composed of the $\mathrm{Cu}-\mathrm{S}-\mathrm{Br}$ positions. Hence, the average growth rates were at first

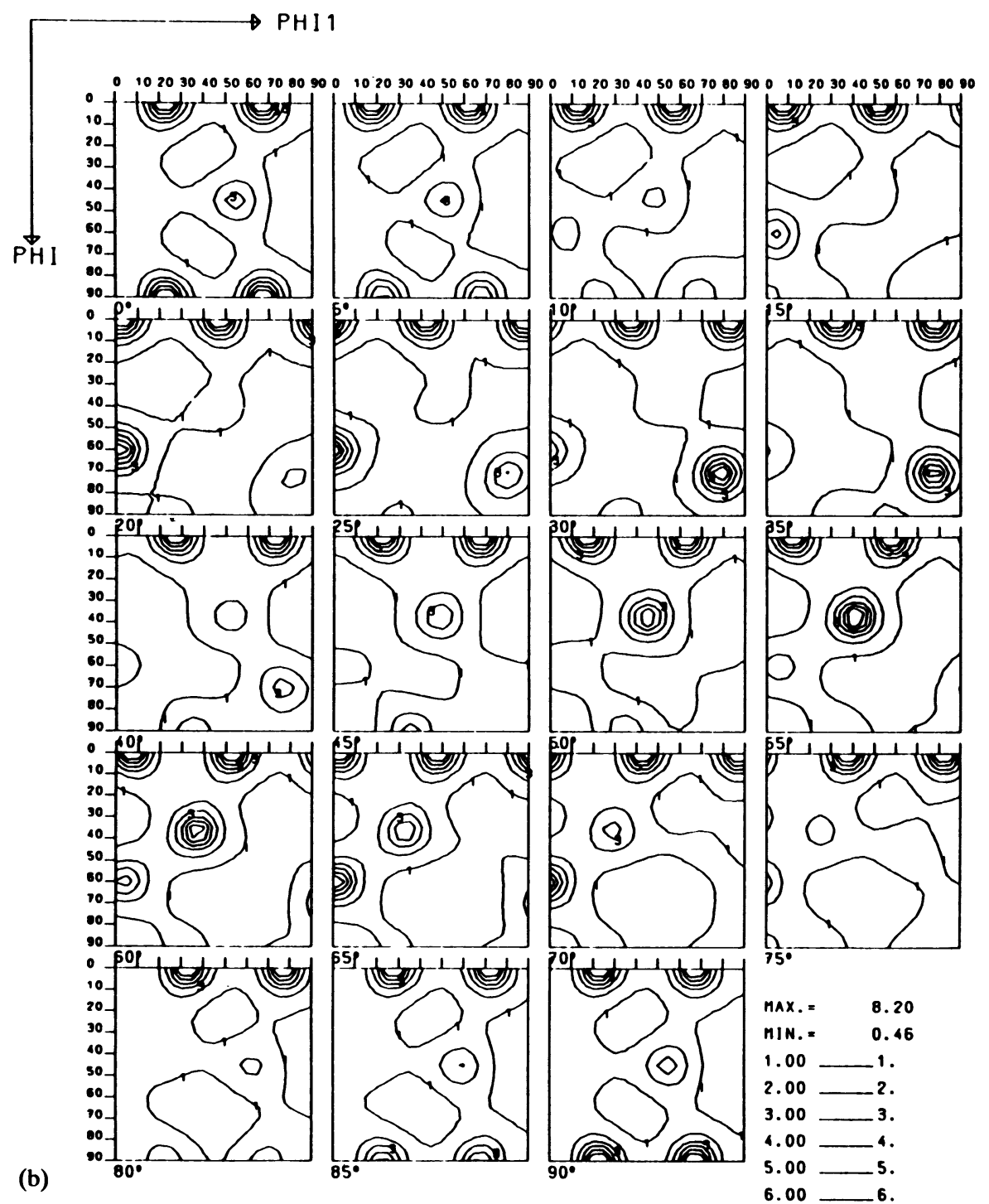

Figure 3 Mean growth rates for deformation textures consisting of only one ideal orientation $g_{0}$ with some spread $\omega_{D}$ about it. The local growth rate was chosen with $\omega_{G}=12.5^{\circ}, W_{0}=0.04$. (a) S-orientation $\omega_{D}=10^{\circ}$, (b) copper orientation $\omega_{D}=10^{\circ}$, (c) brass orientation $\omega_{D}=10^{\circ}$. 
calculated for deformation textures consisting only of each one of these orientations (which comprises, of course, all sample symmetrie variants). The results are shown in Figure 3. It is seen that the S-orientation gives rise to a very high growth rate in the cube orientation. In all other orientations the growth rate is much smaller. Shifting the rolling texture to either brass or copper orientation shifts the maximum growth rate out of the cube position by about $22.5^{\circ}$ in the sense of a rotation about the normal and rolling direction respectively. Addition-

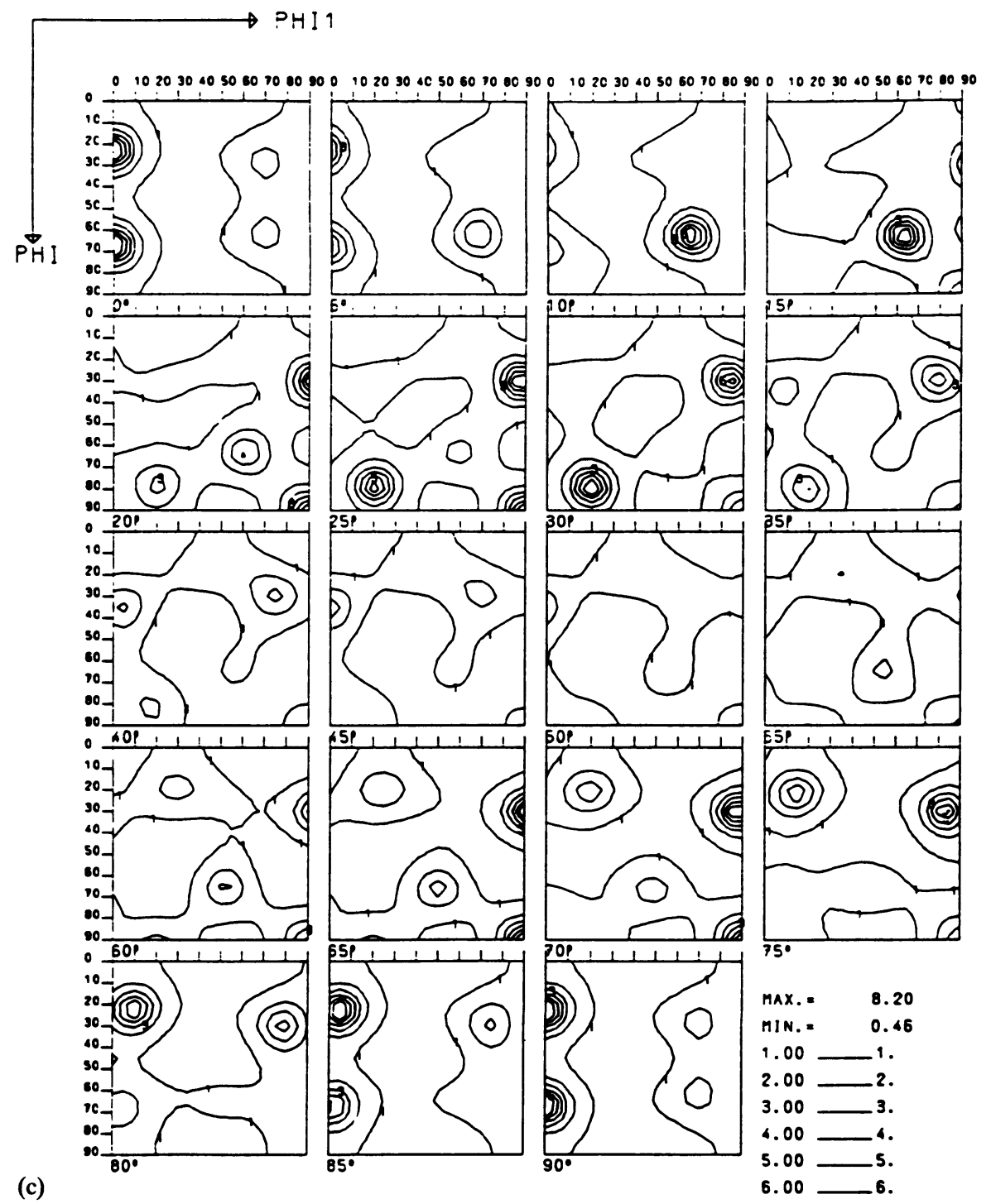

Figure 3 Mean growth rates for deformation textures consisting of only one ideal orientation $g_{0}$ with some spread $\omega_{D}$ about it. The local growth rate was chosen with $\omega_{G}=12.5^{\circ}, W_{0}=0.04$. (a) S-orientation $\omega_{D}=10^{\circ}$, (b) copper orientation $\omega_{D}=10^{\circ}$, (c) brass orientation $\omega_{D}=10^{\circ}$. 
Table 2 Orientations of maximum growth rate for the three main orientations of the deformation texture.

\begin{tabular}{lrrrrrr}
\hline & \multicolumn{3}{c}{ Main } & \multicolumn{3}{c}{ Minor } \\
& $\varphi_{1}$ & \multicolumn{1}{c}{$\Phi$} & $\varphi_{2}$ & $\varphi_{1}$ & $\Phi$ & $\varphi_{2}$ \\
\hline $\mathrm{S}$ & $0^{\circ}$ & $0^{\circ}$ & $0^{\circ}$ & & & \\
$\mathrm{Cu}$ & $23^{\circ}$ & $0^{\circ}$ & $0^{\circ}$ & $55^{\circ}$ & $45^{\circ}$ & $0^{\circ}$ \\
& $0^{\circ}$ & $60^{\circ}$ & $20^{\circ}$ & & & \\
$\mathrm{Br}$ & $0^{\circ}$ & $23^{\circ}$ & $0^{\circ}$ & $0^{\circ}$ & $35^{\circ}$ & $45^{\circ}$ \\
& $90^{\circ}$ & $30^{\circ}$ & $25^{\circ}$ & & & \\
\hline
\end{tabular}

ally, other orientations of preferred growth rate occur which are specified in Table 2.

The next parameter which was varied was the rotation angle $\alpha$ of the local growth rate law which was thus assumed to have its maximum at $\alpha^{\circ}\langle 111\rangle$. The result is shown in Figure 4, considering again the three main components of the deformation texture. It is seen that a pronounced cube orientation is only reached with $\alpha=40^{\circ}$ in the case of the S-orientation. Other pronounced growth orientations are found with $30^{\circ}\langle 111\rangle$ rotation in the case of $\mathrm{Cu}$ type and $\mathrm{Br}$-type rolling texture, which will, however, not be discussed in this paper.

As a further parameter, the spread range $\omega_{G}$ in the local growth rate function was varied. The result is shown in Figure 5. It is seen that the most pronounced cube orientation is obtained with $\omega_{G} \approx 13^{\circ}$.

Also the spread of the S-orientation, as the starting deformation texture, has a strong influence on the mean growth rate. This can be seen in Figure 6 where the maximum growth rate (in the cube orientation) is plotted versus spread angle $\omega_{G}$ of the local growth rate with the spread angle $\omega_{D}$ of the deformation texture as a parameter. One sees, that an extremely sharp peak of the mean growth rate is obtained with decreasing spread of the deformation texture.

Also, no other peaks in the growth rate function are developed in this case. The maximum growth rate as a function of the spread $\omega_{D}$ of the deformation texture is shown in Figure 7. It is seen that these values approach an extremely sharp maximum below $\omega_{D}=8^{\circ}$. (With the actually used parameters for the calculation of distribution functions, i.e. $L=22$ and $\left\{\Delta \varphi_{1}, \Delta \Phi, \Delta \varphi_{2}\right\}=\left\{5^{\circ}, 5^{\circ}\right.$, $\left.5^{\circ}\right\}$ it is not meaningful to follow this maximum to higher values).

The rolling texture of high stacking fault fcc metals consists of a superposition of $\mathrm{S}-\mathrm{Cu}-\mathrm{Br}$ orientation (in various amounts) rather than of the "pure" components. Hence, "mixtures" of these components were assumed as deformation textures. Because of the non-linear nature of Eq. (6), the result cannot be expected to be a "mixture" of the corresponding growth rates of the single components. Figure 8 shows $\varphi_{2}=0$ sections of the three "binary" mixtures. It is seen that a continuous transition from one type to the other takes place whereby the character of the "pure" type prevails up to approximately $25 \%$ of any addition. Finally, Figure 8 also contains the result for the ternary mixture containing equal amounts of the three deformation texture components. Also this latter one gives rise to a preferred growth rate in the cube orientation with a broader spread about it. The additional orientations found with $\mathrm{Cu}$ - and $\mathrm{Br}$-orientation as starting deformation textures, Table 1 , are not developed in this case. 


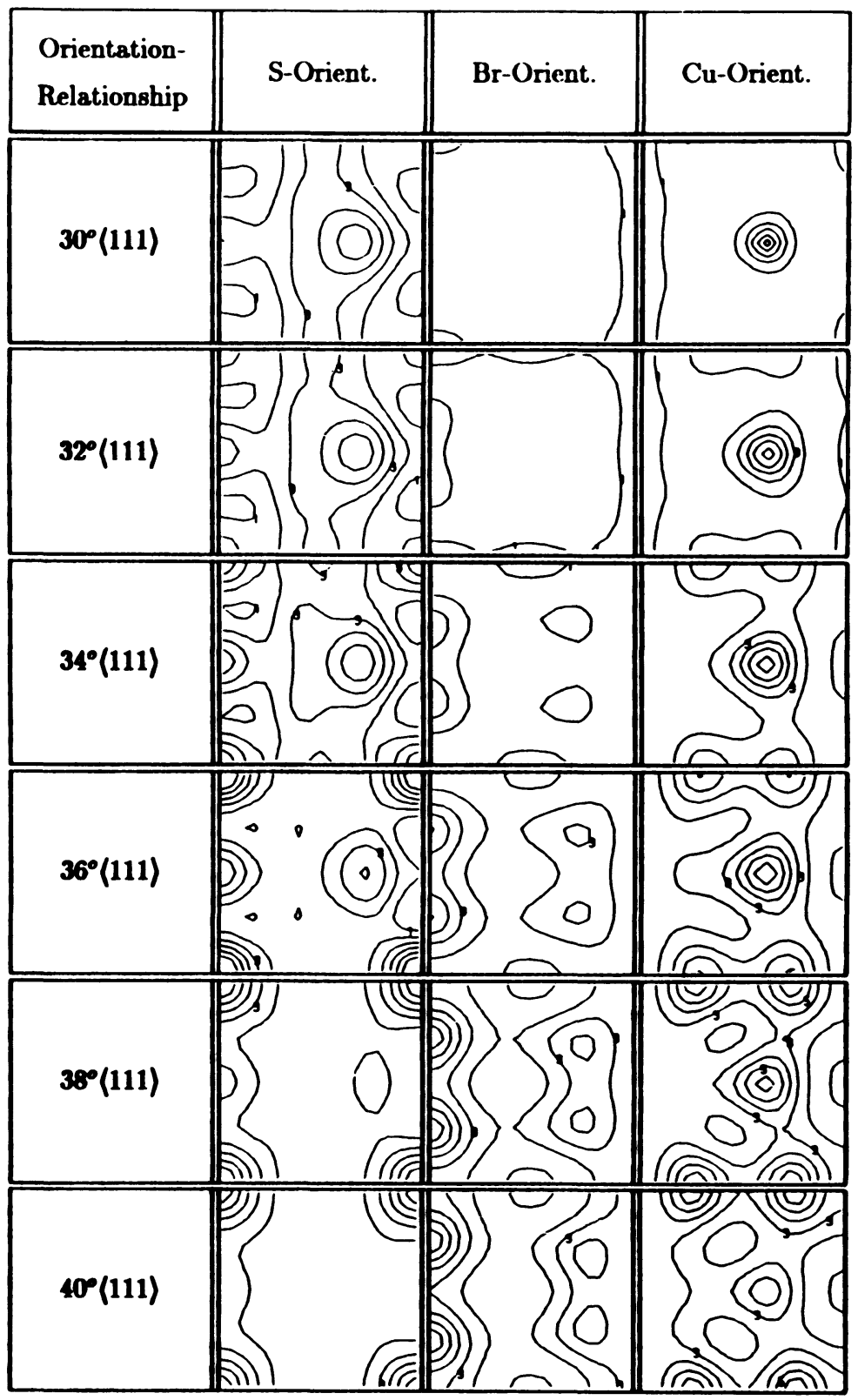

Figure 4 Sections $\varphi_{2}=0$ of the mean growth rate $\bar{W}(g)$ for various rotation angles $\alpha$ in the local growth rate law $\alpha^{\circ}\langle 111\rangle$, calculated for the three main components of the deformation texture. 

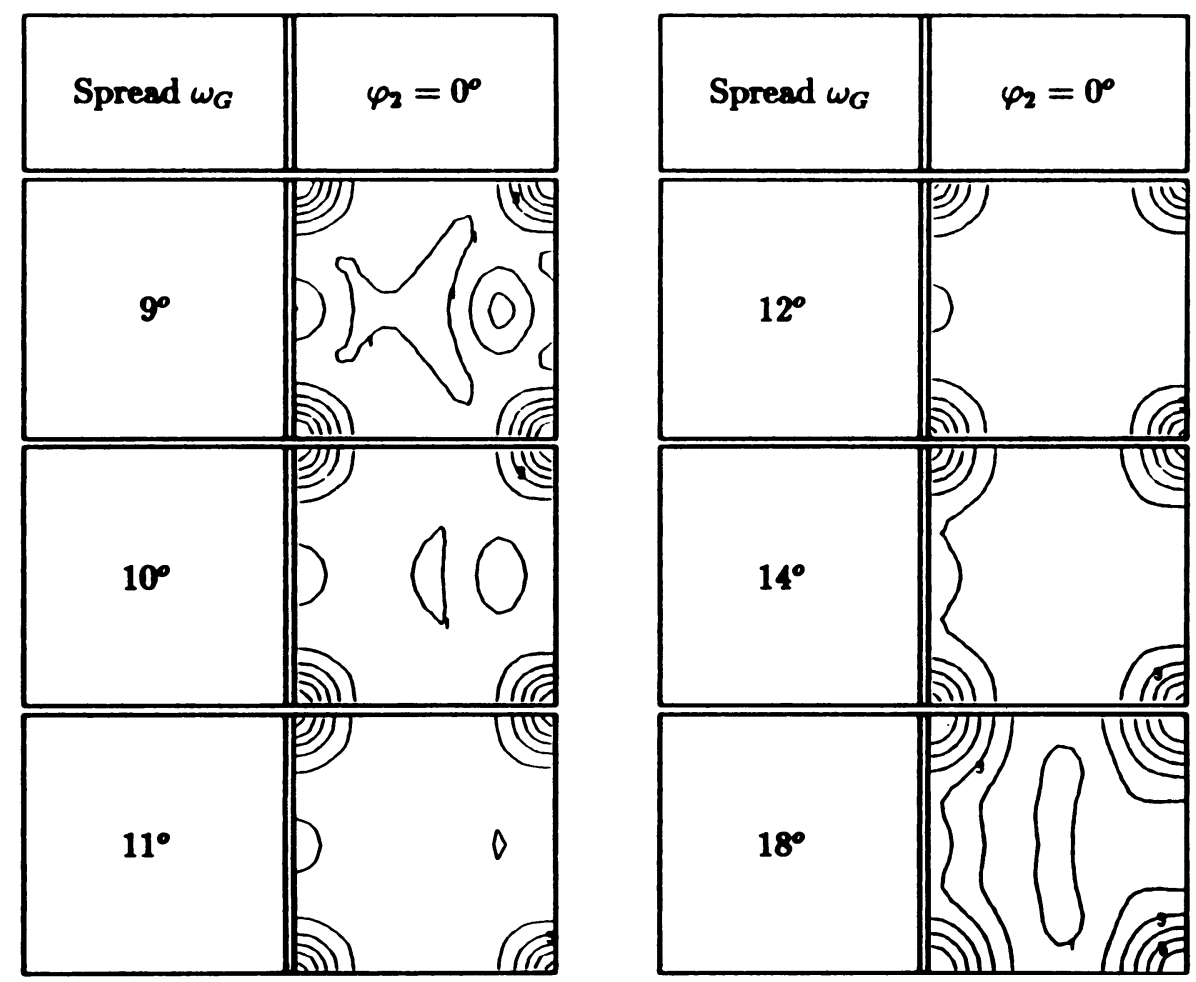

Figure 5 Sections $\varphi_{2}=0$ of the mean growth rate $\bar{W}(g)$ as a function of the spread $\omega_{G}$ in the local growth rate law $40^{\circ}\langle 111\rangle$. The deformation texture was the S-orientation, $\omega_{D}=12^{\circ}$.

The relative amount of $\mathrm{Cu}-\mathrm{S}-\mathrm{Br}$ orientation in the deformation texture is different in different fcc metals and alloys. Figure 9 shows, for instance, the orientation density along the skeleton line $\mathrm{Cu}-\mathrm{S}-\mathrm{Bs}$ found in $\mathrm{Al}-\mathrm{Mn}$ alloys. The $\varphi_{2}=0$ sections of the corresponding experimental recrystallization textures are shown in Figure 10a. Besides the cube orientation with different spread ranges also additional minor components were found in these textures. The intensity distribution along the skeleton line $\mathrm{Cu}-\mathrm{S}-\mathrm{Br}$ of the deformation texture was modelled by a "ternary" mixture of these three components. The corresponding mean growth rates are shown in Figure $10 \mathrm{~b}$. It is seen that this model reproduces already the main features of the experimental recrystallization textures. Even more detailed approximation may be reached by starting from the experimental deformation textures which was, however, not done in this paper.

The rolling texture of low stacking fault fcc metals i.e. brass type texture can be considered as a mixture of the brass- and the Goss-orientation. Hence, binary mixtures of these two orientations were used for the deformation texture. The result is shown in Figure 11. In this figure the sections $0^{\circ} \leq \varphi_{2} \leq 35^{\circ}$ are compared with the corresponding sections of an experimentally determined brass recrystallization texture which can be described by the ideal orientation $\{236\}\langle 385\rangle$. It is seen that neither the brass- nor the Goss texture alone give rise 


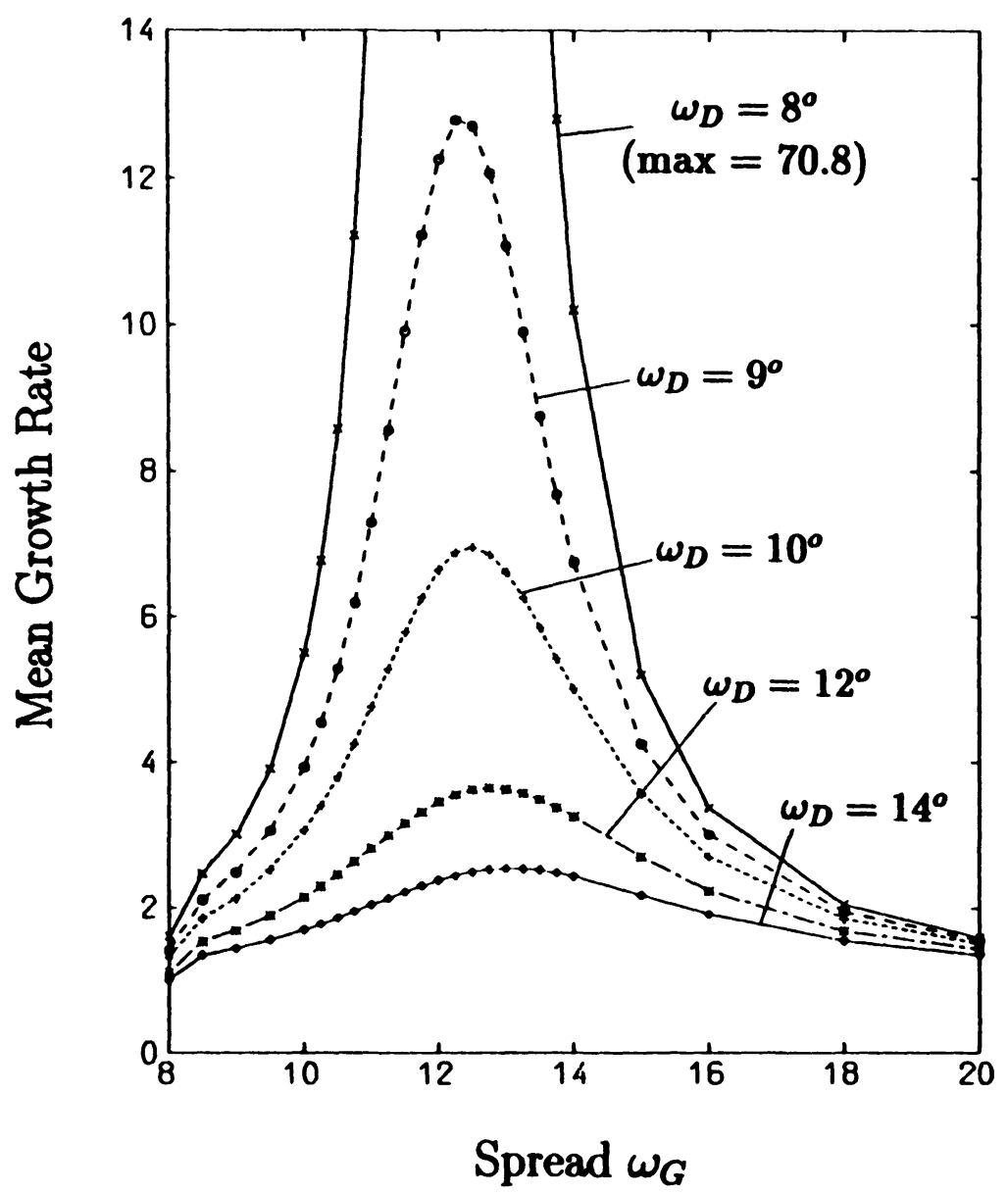

Figure 6 Maximum growth rate in the cube position as a function of the spread $\omega_{G}$ of the local growth rate and the spread $\omega_{D}$ of the S-orientation as the deformation texture.

to preferred growth rates in this orientation. A mixture of about $2 / 3$ brass and $1 / 3$ Goss orientation, however, gives preferred growth rates in nearly exactly this position.

\section{DISCUSSION OF THE RESULTS AND CONCLUSIONS}

In the model of recrystallization texture formation described in Eq. (2) (Bunge and Plege, 1986 and 1987) it was assumed that primary nuclei having a non-random distribution $f^{N}(g)$ may form twins according to Eq. (8). The primary nuclei and the twins together provide the total distribution of nuclei which then grow with a mean linear growth rate according to Eq. (6). In the present paper, we restrict our considerations only to this mean growth rate $\bar{W}(g)$ which depends 


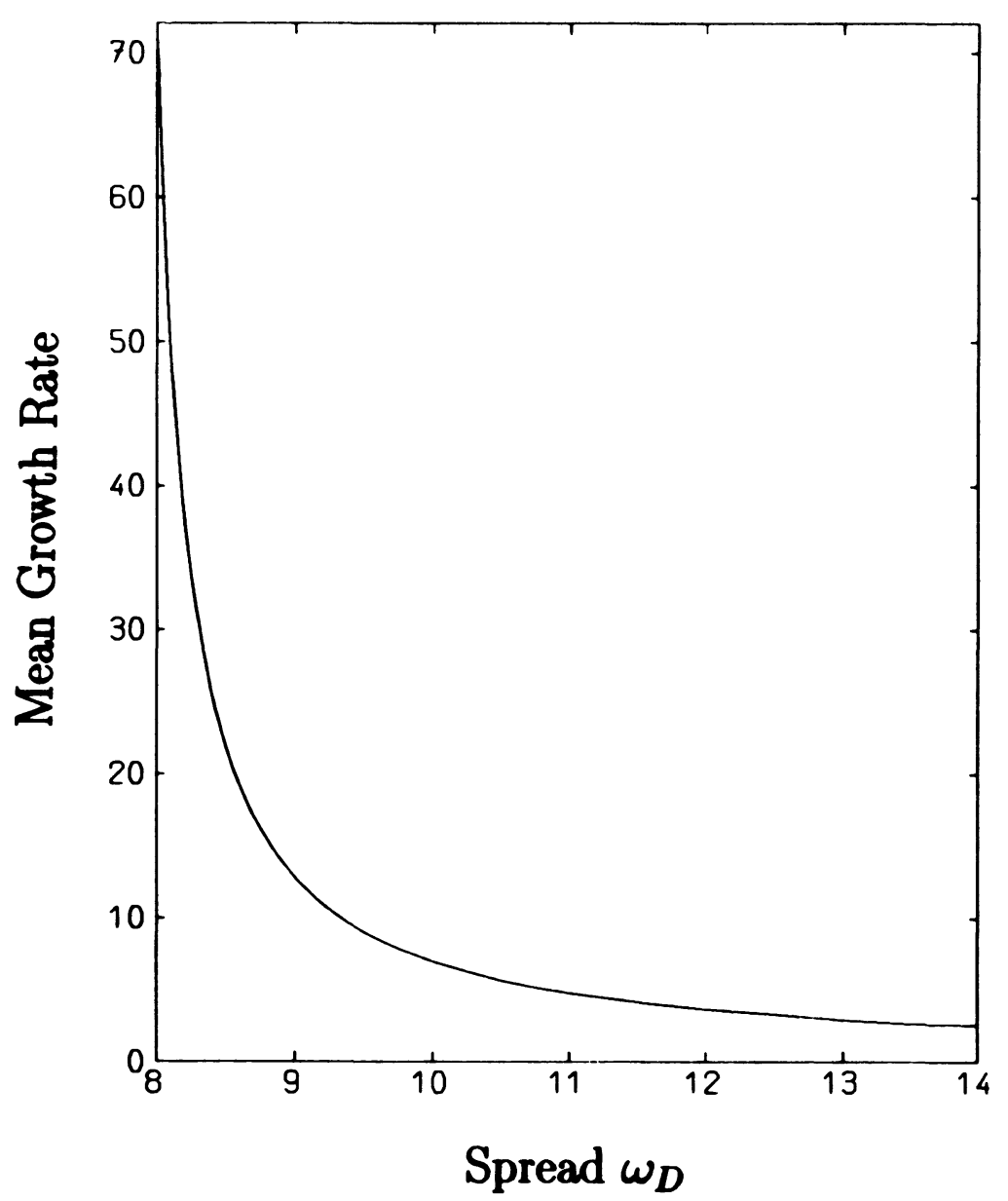

Figure 7 The maximum mean growth rate as a function of the spread angle $\omega_{D}$ of the S-orientation as the starting deformation texture.

on the assumed local growth rate $W(\Delta g)$ and the deformation texture $f^{D}\left(g^{D}\right)$ into which the nuclei must grow. Eq. (6) is the quantitative formulation of what has been called a "compromise" texture (Schmidt et al., 1975; Bunge, 1966) i.e. an orientation which grows sufficiently fast into all deformation texture components which may comprise several sample symmetric variants, each. An orientation which has zero local growth rate in any of the deformation texture components will be stopped in this component and thus will not reach the other deformation texture components in which it might have a faster growth rate. Hence, the mean growth rate of such an orientation must be zero.

It is evident that a "compromise" texture depends essentially on the spread ranges of the deformation texture components and of the local growth rate law. (Assuming ideal orientations, only, and an ideal growth rate law, e.g. $40^{\circ}\langle 111\rangle$, would not allow any compromise and the mean growth rate would be zero). This expresses itself in the non-linear nature of Eq. (6). 

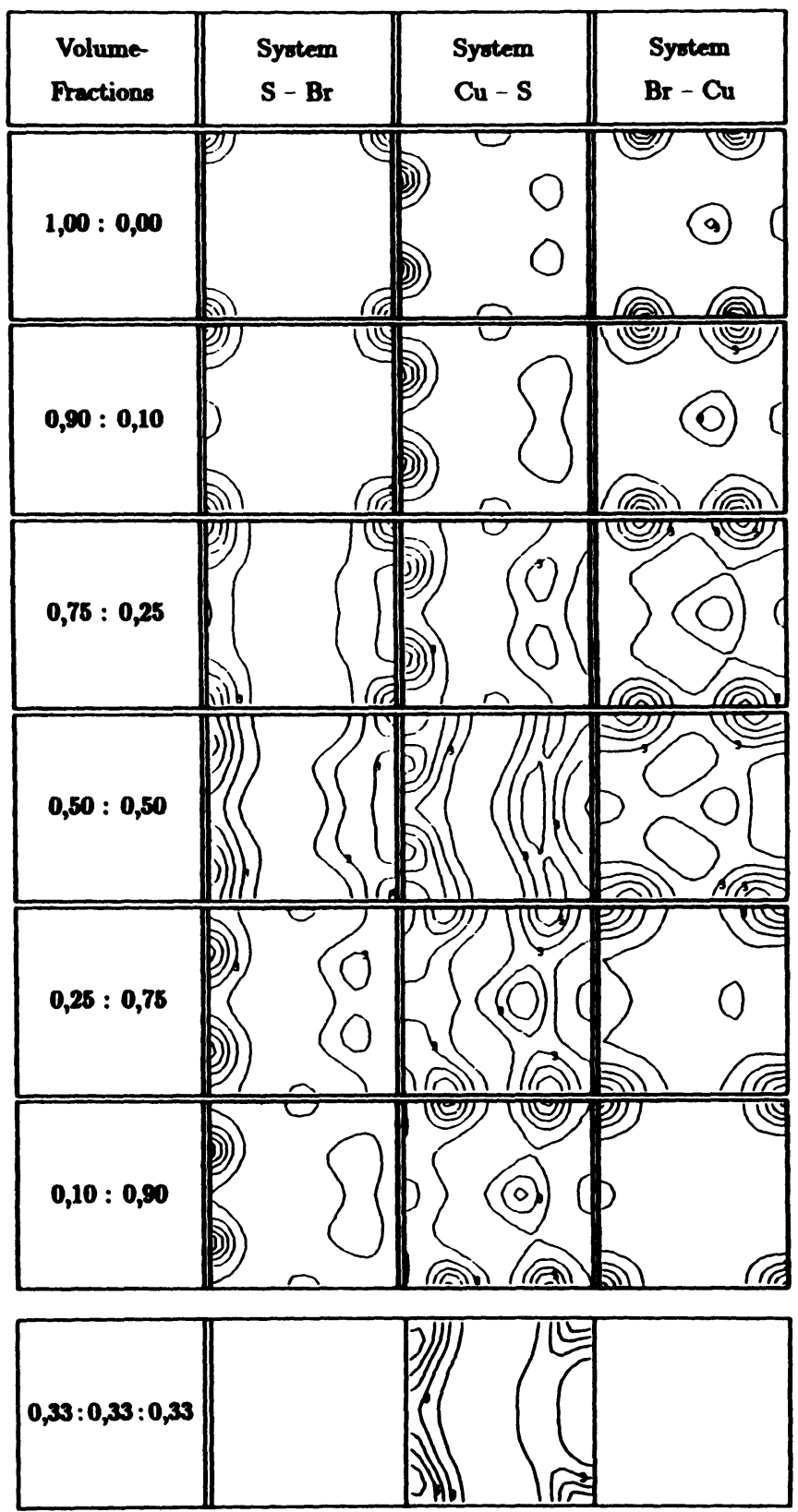

Figure 8 Sections $\varphi_{2}=0$ of the mean growth rate $\bar{W}(g)$ for "binary" mixtures of S-, copper, and brass orientation as well as for the ternary mixture $(1 / 3,1 / 3,1 / 3)$. 


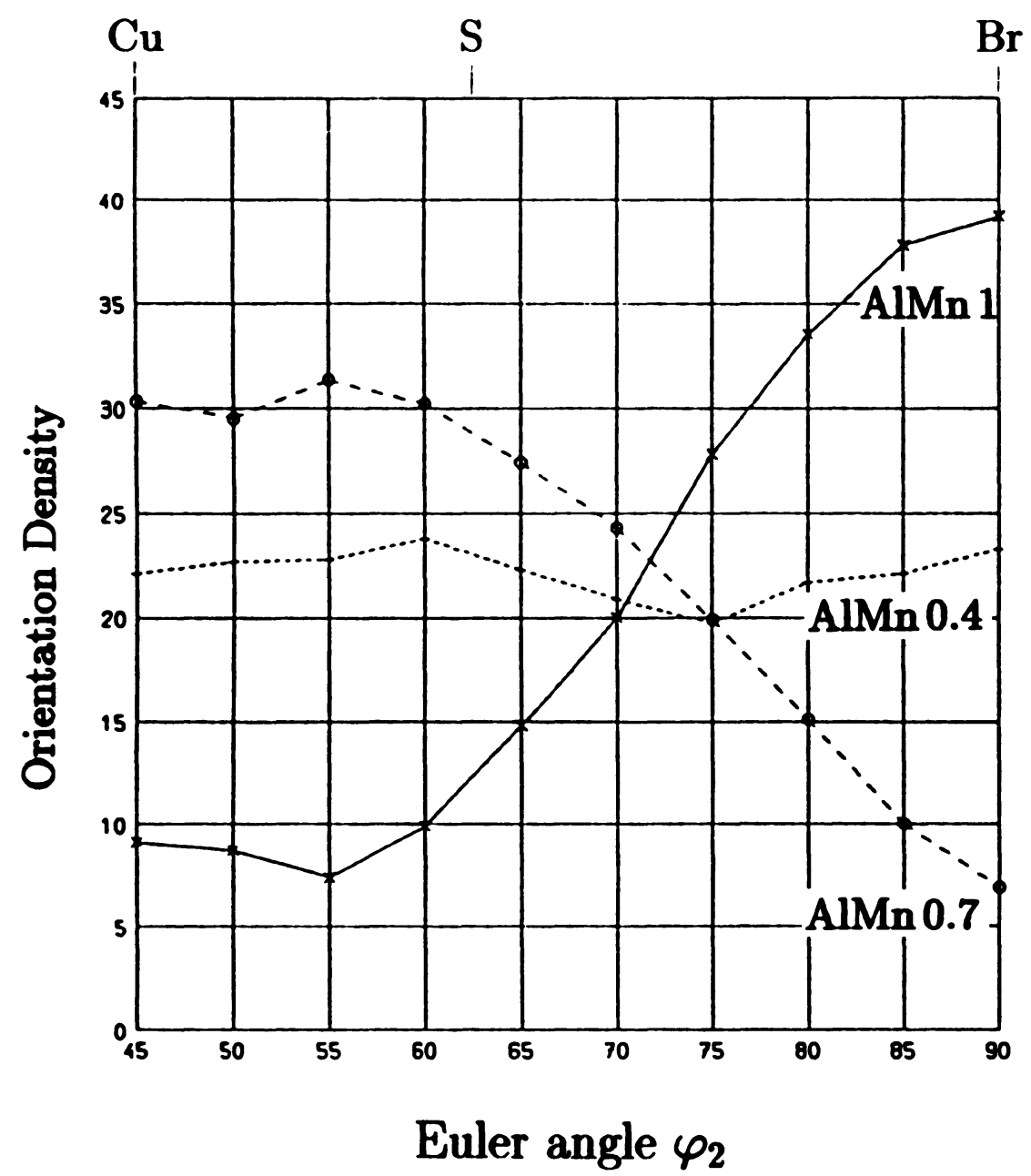

Figure 9 Orientation density along the skeleton line of the rolling texture of three Al-Mn alloys.

In Eq. (6) the deformation texture $f^{D}\left(g^{D}\right)$ is a rather well-known quantity for a great number of materials and deformation states. The local growth rate function $W(\Delta g)$, on the other hand, is not known very well. To our knowledge, a complete determination of this function in the complete misorientation space $g=\left\{\Delta \varphi_{1}, \Delta \Phi, \Delta \varphi_{2}\right)$ has not been carried out. On the other hand, much evidence has been provided in the literature supporting the preferred growth orientation relationship $\sim 40^{\circ}\langle 111\rangle$ found in the classical investigation by Liebmann, Lücke and Masing. It is, thus, reasonable to assume this orientation relationship of preferred growth and to extend it into the three-dimensional misorientation space $\Delta g$ by assuming "Gaussian" spread about it in all three angular directions. With these assumptions mean growth rates were calculated.

As a first result a very sharp peak of the mean growth rate was found in the 


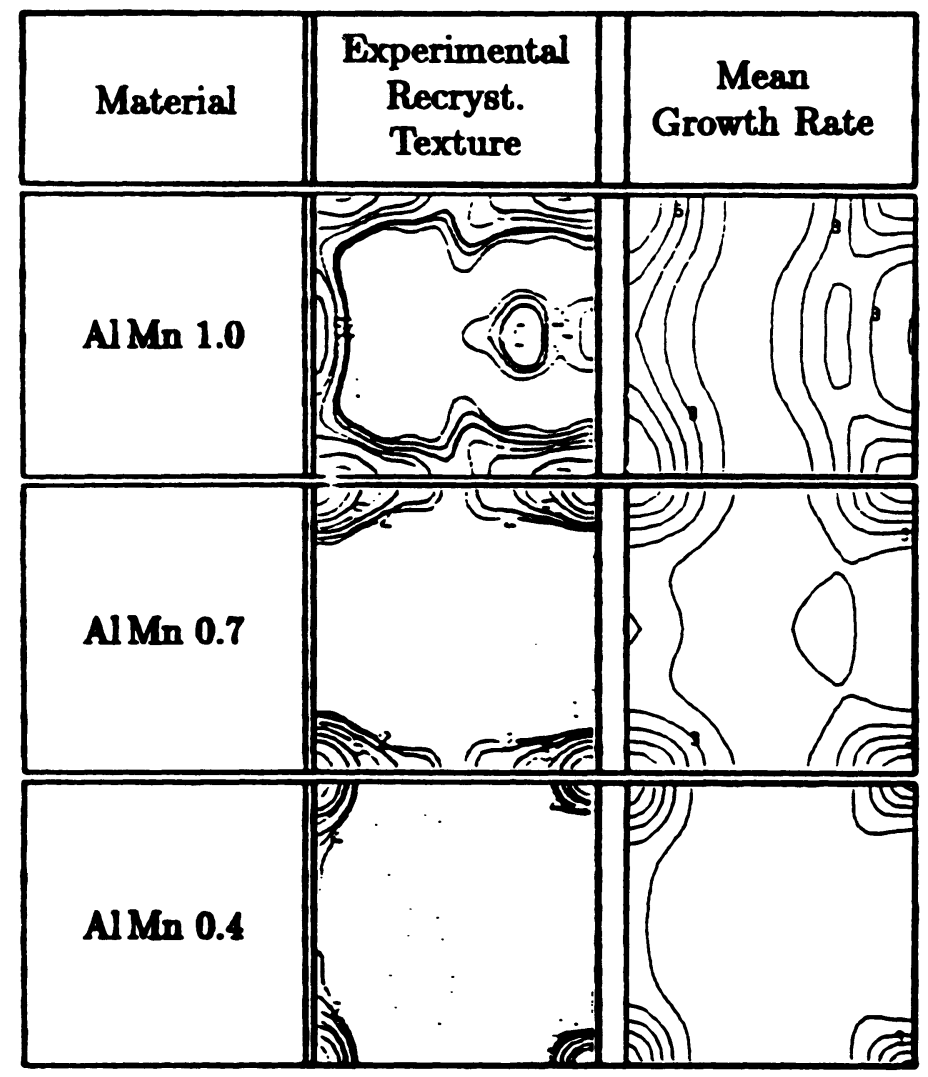

Figure 10 Sections $\varphi_{2}=0$ of the recrystallization textures obtained from the three deformation textures of Figure 9 compared with the calculated growth rate for a ternary mixture $\{\mathrm{Cu}, \mathrm{S}, \mathrm{Br}\}$.

cube orientation (with no other preferred growth orientations) assuming a spread $\omega_{G}=12^{\circ}$ about the $40^{\circ}\langle 111\rangle$ relation as is shown in Figure 6 , if one starts with a deformation texture consisting only of the S-orientation. This peak becomes extremely high with decreasing spread of the S-orientation. The cube orientation is not obtained from the copper or from the brass orientation. It is, however, obtained from a reasonable mixture of these three orientations which corresponds to real deformation textures. Hence, the formation of the cube recrystallization texture can be explained within this model by growth selection, alone. This result is also corroborated by Figure 10 which shows that certain modifications of the deformation texture lead to similar modifications in the mean growth rate as are observed in the corresponding experimental recrystallization textures.

In brass the recrystallization texture can be idealized by the orientation $\{236\}\langle 385\rangle$. A preferred growth rate in nearly the same orientation is found with the same local growth rate law $40^{\circ}\langle 111\rangle, \omega_{G}=12^{\circ}$ when the starting texture is a mixture of about $70 \%$ brass orientation and $30 \%$ Goss orientation which is a good model of the experimental brass deformation texture. The brass orientation $\{110\}\langle 112\rangle$ alone gives a growth rate distribution which is much less similar to 

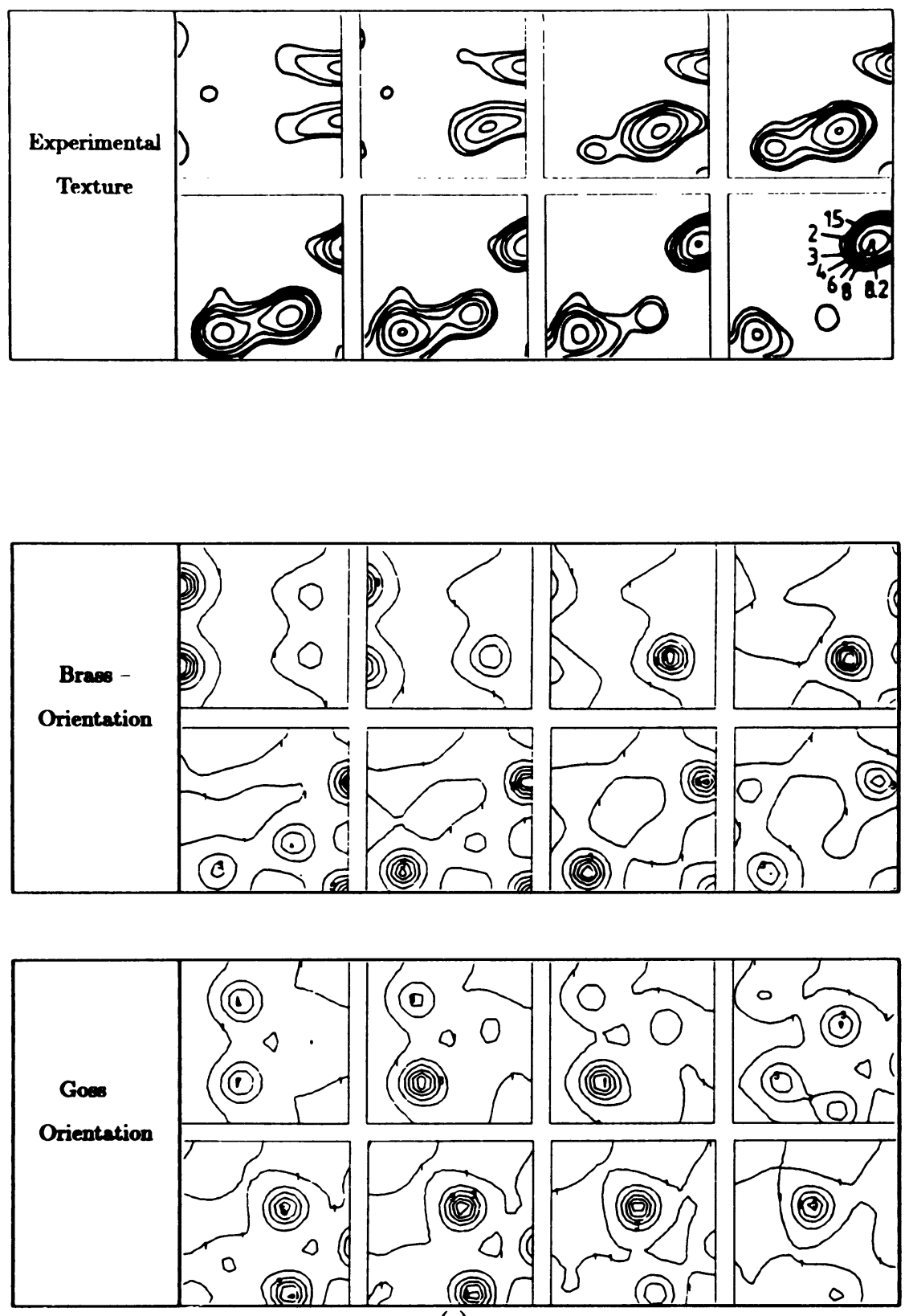

(a)

Figure 11 Sections $0^{\circ} \leq \varphi_{2} \leq 35^{\circ}$ of the mean growth rate calculated with $\Delta g_{0}=40^{\circ}\langle 111\rangle, \omega_{G}=12.5^{\circ}$ and $W_{0}=0.04$ for different "binary" mixtures of the brass and Goss orientation as the starting deformation textures, compared with the corresponding sections of an experimental recrystallization texture. 

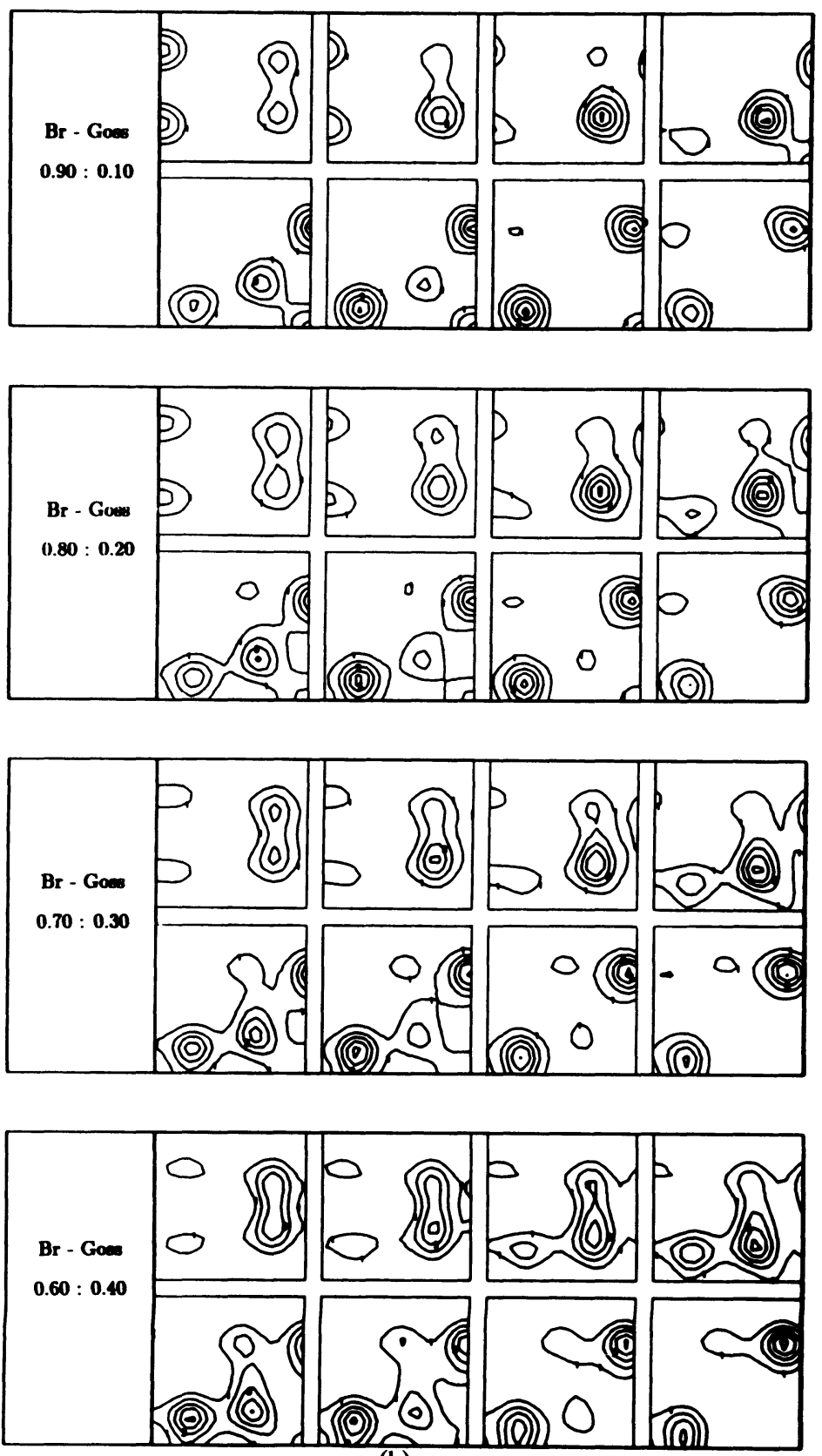

(b)

Figure 11 Sections $0^{\circ} \leq \varphi_{2} \leq 35^{\circ}$ of the mean growth rate calculated with $\Delta g_{0}=40^{\circ}\langle 111\rangle, \omega_{G}=12.5^{\circ}$ and $W_{0}=0.04$ for different "binary" mixtures of the brass and Goss orientation as the starting deformation textures, compared with the corresponding sections of an experimental recrystallization texture. 
the experimental recrystallization texture. On the other hand, if one considers the "compromise orientations" obtained from the $\{110\}\langle 112\rangle$ with the $40^{\circ}\langle 111\rangle$ growth rate law only quantitatively then, besides $\{236\}\langle 385\rangle$, two other orientations, i.e. $\{130\}\langle 001\rangle$ and $\{112\}\langle 110\rangle$ are found (see e.g. Duggan et al., 1990; Hirsch, 1988). These orientations are, however, not observed in the experimental recrystallization texture. Hence, it was concluded, (Duggan et al., 1990; Hirsch, 1988) that these two compromise orientations could not grow because of missing nuclei. This was a strong argument for combined action of preferred orientation and growth selection. The present quantitative calculations, however, show, that the growth "compromise" in these latter two orientations is so much worse that these orientations are not really fast-growing ones compared with the main orientation $\{236\}\langle 385\rangle$. Hence, also the brass recrystallization texture can be understood solely on the basis of growth selection assuming the classical Liebmann, Lücke, Masing relationship $40^{\circ}\langle 111\rangle$.

It must be emphasized, that these arguments do not exclude the occurrence of preferentially oriented nuclei. They only show that the growth rate factor $\bar{W}(g)$ in Eq. (2) has already the form of the experimentally determined recrystallization textures in the considered examples. In most cases the orientation dependence of this factor (especially since it enters Eq. (2) in the third power) is so strong that it overrides the influence of the distribution function of the nuclei which must be assumed to be a much flatter function. Nevertheless, it does not seem reasonable to assume totally random distribution of nuclei $f^{N}(g) \equiv 1$. Hence, it will be necessary to study, by further model calculations, how the factor $f^{N}(g)$ may modify the final recrystallization texture $f^{R}(g)$ within the present model expressed by Eq. (2).

An alternative model to a compromise texture is the "superposition texture". The quantitative formulation of this concept would be expressed by averaging $W(\Delta g)$ with the deformation texture instead of $W(\Delta g)^{-1}$ as in Eq. (6). The superposition texture may be expected if the mean distance between the nuclei is smaller than the grain size of the deformed material. In this case each deformation texture component recrystallizes by its own. If the distance of the nuclei is, however, much greater than the deformed grains, then a compromise texture is to be expected (see e.g. Bunge, 1966). The superposition model has been tested by Pospiech and Lücke (1979). The model reproduces the main recrystallization orientations fairly well but it is not satisfactionary in detail. The superposition and the compromise model have also been compared in calculations by Sztwiertnia and Pospiech (1986). In this case, however, an expression for the compromise model different from Eq. (6) was used which did not give rise to growth rates simulating, by themselves, the brass recrystallization texture. These authors thus concludes, that oriented nucleation was an essential factor in the formation of the brass recrystallization texture.

As was already mentioned, the ratio between the distance of nuclei and the size of the deformation texture components determines whether a superposition or a compromise model should be applicable. Duggan et al. (1990) concluded that in the early stages of the formation of the cube texture in copper the superposition model should be valid and that the compromise model may become effective only at later stages. Because of the $\bar{W}^{3}$-dependence of the recrystallized volume fraction, however, these later stages constitute a major part of the recrystallization texture. 
The present calculations, using a strictly formulated compromise model (Eq. (6)) show that the final recrystallization textures of copper and brass can be very well understood on the basis of oriented growth alone, using the compromise model.

\section{References}

Beck, P. A. (1949). J. appl. phys. 20, 633.

Bunge, H. J. (1966). Rekristallisation metallischer Werkstoffe, ed. Schulze, G. E. R. and Ringpfeil, H., VEB Deutscher Verlag für Grundstoffindustrie, Leipzig, 39.

Bunge, H. J. and Plege, B. (1987). Theoretical Methods of Texture Analysis, ed. Bunge, H. J., DGM Informationsgesellschaft, Oberursel, 289.

Bunge, H. J. and Plege, B. (1986). Annealing Processes, Recovery, Recrystallization and Grain Growth, ed. Hansen, N. et al., Risø 261.

Burgers, W. C. and Louwers, P. C. (1931). Z. Physik 61, 605.

Duggan, B. J., Sindel, M., Köhlhoff, G. D. and Lücke, K. (1990). Acta Met. 38, 103.

Hirsch, J. (1988). Habilitation Thesis, Aachen.

Liebmann, B., Lücke, K. and Masing, G. (1956). Z. Metallkunde 47, 57.

Plege, B. (1983). Doctoral Thesis, Clausthal.

Pospiech, J. and Lücke, K. (1979). Z. Metallkunde 70, 567.

Schmidt, U., Lücke, K. and Pospiech, J. (1975). Proc. 4th Int. Conf. on Textures of Materials, London, 147.

Sztwiertnia, K. and Pospiech, J. (1986). Archiwum Hutnictwa 31, 627. 